\title{
Physical processes of summer extreme rainfall interannual variability in eastern China: Part I-observational analysis
}

\author{
Fangxing Tian ${ }^{1,4}$ (D) Sihan $\mathrm{Li}^{2} \cdot$ Buwen Dong ${ }^{1} \cdot$ Nicholas P. Klingaman $^{1} \cdot$ Nicolas Freychet $^{3} \cdot$ Sarah Sparrow $^{2}$
}

Received: 24 June 2021 / Accepted: 28 December 2021 / Published online: 20 January 2022

(c) The Author(s) 2022

\begin{abstract}
Extreme precipitation can have catastrophic effects in China by triggering floods, landslides, and other natural disasters. We measure extreme precipitation over eastern China by the maximum of five-day precipitation amount (Rx5day) in June, July, and August (JJA), which contributes more than $20 \%$ of the climate mean of JJA regional total precipitation. Based on the empirical orthogonal teleconnection (EOT) method, this work identifies four dominant regions of observed Rx5day interannual variability in eastern China: north-eastern China (EOT1), the southern lower reaches of the Yangtze valley (EOT2), southern China (EOT3) and the northern lower reaches of the Yangtze valley (EOT4). EOT1 extreme precipitation is related to a strong East Asian Summer Monsoon (EASM), a weak monsoon front and a northward displaced upper-tropospheric westerly jet. EOT2 and EOT4 extreme precipitation are related to an enhanced and stable monsoon front and a strong western North Pacific subtropical high (WNPSH). The WNPSH associated with EOT4 is stronger than that associated with EOT2, which pushes the monsoon front further north. EOT3 represents extreme precipitation that is related to anomalous southerlies around the western ridge of the WNPSH. The southerlies transport warm and moist air to southern China and increase precipitation there. The four key regions and the related mechanisms are not sensitive to the EOT technique, as the EOT-based extreme precipitation patterns and circulation anomalies are confirmed using Self-Organising Maps (SOMs).
\end{abstract}

Keywords Extreme precipitation $\cdot$ Rx5day $\cdot$ Monsoon front $\cdot$ Upper-tropospheric westerly jet $\cdot$ Moisture budget $\cdot$ Western North Pacific subtropical high (WNPSH) · Empirical orthogonal teleconnection (EOT) · East Asian Summer Monsoon ·

Self-Organising Maps (SOM)

\section{Introduction}

Precipitation is a key component of the hydrological cycle, but extreme precipitation can cause catastrophic impacts for human society and the natural environment. China is vulnerable to floods and other natural disasters related to extreme precipitation. For example, floods in 1998 caused about $\$ 36$

Fangxing Tian

fangxing.tian@reading.ac.uk

1 Department of Meteorology, National Centre for Atmospheric Science, University of Reading, Reading, UK

2 Department of Engineering Science, Oxford e-Research Centre, University of Oxford, Oxford, UK

3 School of Geosciences, University of Edinburgh, Edinburgh, UK

4 Geophysical Institute, University of Bergen and Bjerknes Centre for Climate Research, Bergen, Norway billions of total losses and over 3000 flood-related fatalities (NCC 1998). Heavy precipitation in 2020 caused flash flooding, urban flooding, and landslides particularly along the Yangtze River basin (Wu et al. 2021). Such catastrophes are likely to become more frequent. In a warming climate, the model-projected changes in extreme precipitation are stronger than those for mean precipitation (Kitoh et al. 2013; Zhou et al. 2014). In China, extreme precipitation is projected to become more frequent and intense (Guo et al. 2016; Chen and Zhou 2017; Li et al. 2017). Specifically, the maximum 5-day precipitation (Rx5day) in China is projected to increase by $6.52 \%$ per degree Celsius of global warming (Zhang and Zhou 2020). Considering the large population (Piao et al. 2010) and the fast-growing economies (Hubacek et al. 2007) of eastern China, a better understanding and a more accurate prediction of extreme precipitation over this region at a high temporal and spatial resolution is crucial for early warnings, and therefore reducing the disastrous impacts. 
Summer precipitation and precipitation extremes in eastern China are influenced by different systems. The monsoon front system, a quasi-stationary subtropical front, is the primary rain-producing system in the East Asian Summer Monsoon (EASM). Much of the summer convective rainfall in China is produced along the narrow frontal zone (Ding 2004; Ninomiya 2004; Ding and Chan 2005). Another important system is the western North Pacific subtropical high (WNPSH), the interannual variations of which are significantly correlated with water vapor flux variations in East Asia. Variations of the location and direction of the circulation around the western flank of the WNPSH influence the EASM and its related precipitation in eastern China (Zhang et al. 2017). Chang et al. (2000a, b) also showed that a stronger and westward-extended WNPSH causes heavier rainfall along the Yangtze River Valley. The East Asian upper-tropospheric jet stream (EAJS) is another crucial system for summer precipitation variability over eastern China (Lin and Lu 2005). In the mid-latitudes, the spatial distribution of summer precipitation in China is modified by the summer westerly jet (Hong and Lu 2016). Lin (2013) showed that enhanced westerlies north of the EAJS axis increase rainfall significantly in northeast China and decrease rainfall in the Yellow River-Huaihe River valleys.

Considering the vast territory and complex topography of China, the mechanisms of extreme precipitation vary regionally. Therefore, we aim to identify the key regions of extreme precipitation in eastern China and find the dominant mechanisms for interannual variations of extreme precipitation in each region. To demonstrate that the key regions and mechanisms we identify are not sensitive to the choice of method, we use two independent classification techniques to verify our results (see Sect. 2).

The structure of this paper is as follows. Section 2 describes the data and methods. The results from one classification technique, Empirical Orthogonal Teleconnections (EOTs), are shown in Sect. 3. The results from a second classification technique, Self-Organizing Maps, are presented in Sect. 4. The conclusions are summarized in Sect. 5.

\section{Data and methods}

\subsection{Data}

We use precipitation data from the observational dataset over China developed by Wu and Gao (2012, named CN05.1) from 1961 to 2017 with a resolution of $0.25^{\circ}$ latitude by $0.25^{\circ}$ longitude. The dataset is based on interpolating over 2400 observation stations in China. Data for large-scale precipitation and circulation fields, which are the specific humidity, horizontal wind, sea level pressure, geopotential height at $500 \mathrm{hPa}$, sea surface temperature and outgoing longwave radiation in 1979-2017 are from the fifth-generation reanalysis from ECMWF (ERA5). ERA5 provides several improvements compared to the ERA-Interim dataset (Hersbach et al. 2020).

\subsection{Methods}

\subsubsection{Rx5day}

The Commission for Climatology/Climate Variability and predictability/Joint WMO-IOC Technical Commission for Oceanography and Marine Meteorology Expert Term on Climate Change Detection and Indices (ETCCDI) have recommended 11 extreme precipitation indices to identify the intensity, frequency, and duration of precipitation (http://etccdi.pacificclimate.org/list_27_indices.shtml). In this study, we use the maximum consecutive 5-day precipitation totals (Rx5day) in summer (June, July, August: JJA) to identify extreme summer precipitation in China. Consecutive 5-day precipitation can distinguish the extreme events of synoptical scale from the mesoscale events ( 1 day or less, from around $5 \mathrm{~km}$ to several hundred $\mathrm{km}$ ). The accuracy of reanalysis data on short temporal scales, particularly early in the record when fewer observations were available. We would expect reanalysis data to capture more accurately features on larger spatial and longer temporal scales, such as those features related to Rx5day. The synoptical precipitation events are normally related to some weather system, such as the high/low pressure system, which can be identified in the observation data, reanalysis data used in this work and can be simulated by climate models used in Part II of this study (Freychet et al. 2021).

\subsubsection{Empirical orthogonal teleconnections (EOTs)}

To identify independent regions of extreme precipitation in eastern China, we use the Empirical Orthogonal Teleconnections (EOTs; Smith 2004; van den Dool et al. 2000) technique. Unlike Empirical Orthogonal Functions (EOFs), which are orthogonal in both space and time, EOTs are orthogonal either in space or time. In this work, we choose orthogonality in time to investigate temporal rainfall variability. The original EOT technique of van den Dool et al. (2000) identifies EOTs by selecting the point (the EOT "base point") that describes the most space-time variance at all other points in the domain. As addressed in Stephan et al. (2018) for China, following Smith (2004) for Australia, a large fraction of total rainfall variance is concentrated in relatively small areas, primarily along the coast. Therefore, instead of using the total rainfall variance, we follow Smith (2004) and identify the first EOT (EOT1) base point as the point that explains the most variance in the domain-averaged rainfall. For EOT1, we calculated the correlation coefficients 
between the timeseries of domain-averaged rainfall and the timeseries on each grid point, and took the grid point with the maximum correlation coefficient as the base point. The timeseries on the base point is the timeseries of EOT1. The associated EOT1 spatial pattern is the map of correlation coefficients at each other point with the base point. To calculate the EOT2, the spatial pattern of precipitation associated with EOT1 is removed from all the grid points by linear regression. The EOT2 base point and timeseries are calculated from the residual data, and so on for the third and subsequent EOTs. In this work, we analysed the first 4 EOTs, as each of them explains more than $8 \%$ of the variance of the domain-averaged timeseries.

\subsubsection{Self-Organising Maps (SOMs)}

We use the Self-Organising Maps (SOMs) technique (Kohonen 2001; Sheridan and Lee, 2011) as a secondary supporting tool to analyse the 5-day precipitation and to verify the results of the EOT analysis. SOM is essentially an unsupervised learning technique that organizes multidimensional input data into an organized topological 2-D array which are more interpretable, and each element/member of this array is denoted as a SOM node (Kohonen 2001; Reusch et al. 2005; Lennard and Hegerl 2014); in this study, each node represents a characteristic extreme precipitation pattern over eastern China. The motivation for applying SOMs is that nonlinearity is not suppressed, hence smoother intermediate patterns can be extracted; nor does it require prior knowledge of which type of patterns might be detected or emerge. Previous studies (e.g., Reusch et al. 2005) have suggested that the advantages of SOMs over more traditional pattern recognition and dimension-reduction methods (e.g., principal component analysis PCA) become more apparent as the number of patterns retained by SOMs increases. The number of SOM patterns to retain is a balance between resolution (keeping enough to efficiently represent variability in the data) and interpretability (not too many so that physical interpretability between the different patterns is retained). We test various node configurations (smaller and larger), to arrive at a reasonable node configuration ( 5 by 4 ), beyond which the added value of increasing node numbers is minimal. It is very important to note that unlike the EOTs applied in this study, which are orthogonal in the time dimension, in SOMs the data are treated as a continuum rather than discretized. It is beneficial to see whether common patterns emerge from applying these two different methods.

\section{Results}

\subsection{The regions of coherent extreme precipitation variability}

The largest Rx5day values are mainly distributed in eastern China, with a maximum up to $160 \mathrm{~mm}$ along the Yangtze River and in southeast China (Fig. 1a). The climatological summer total precipitation has a maximum up to $800 \mathrm{~mm}$ in southern China and decreases to the north (Fig. 1b). The ratio of Rx5day to the summer total precipitation (Fig. 1c) shows that Rx5day contributes more than $20 \%$ of total summer precipitation, with a maximum up to $30 \%$ along the Yangtze River east of $105^{\circ} \mathrm{E}$. These results indicate not only that maximum Rx5day precipitation occurs in eastern China, but also that it contributes a large fraction of summer total precipitation in the region. Therefore, understanding
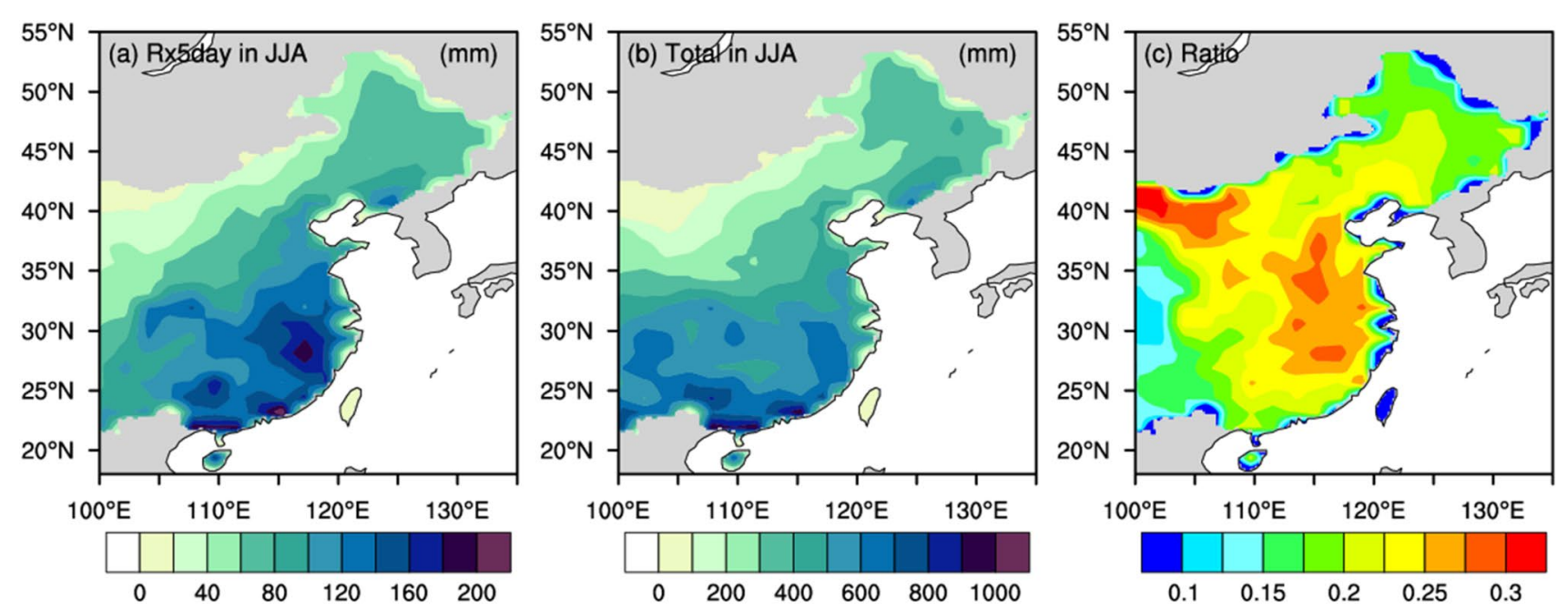

Fig. 1 a Climatological mean summer Rx5day and b mean summer total precipitation (mm) over eastern China during 1961-2017. c ratio of summer Rx5day to summer total precipitation, based on the data CN05.1. Note colour scales are different in panels $\mathbf{a}$ and $\mathbf{b}$ 
extreme precipitation variations, as a contribution to an early warning system, would reduce their damaging socioeconomic impacts and benefit human well-being.

The complex topography and multiple climate zones in China lead to an inhomogeneous distribution of Rx5day, as shown in Fig. 1a. We perform EOT analysis on Rx5day variations over eastern China $\left(105^{\circ} \mathrm{E}-135^{\circ} \mathrm{E}\right)$ and choose the EOTs based on the method in Sect. 2.2.2 for further analysis. As shown in Table 1, EOT1 describes Rx5day

Table 1 The explained variance, location of base points and the indicated regions of extreme precipitation of leading four EOTs

\begin{tabular}{llll}
\hline & $\begin{array}{l}\text { Explained } \\
\text { variance }(\%)\end{array}$ & Base point & Region \\
\hline EOT1 & 28.6 & $42^{\circ} \mathrm{N} 121^{\circ} \mathrm{E}$ & North-eastern China \\
EOT2 & 22.1 & $28^{\circ} \mathrm{N} 117^{\circ} \mathrm{E}$ & South of the Yangtze River \\
EOT3 & 12.4 & $24^{\circ} \mathrm{N} 113^{\circ} \mathrm{E}$ & Southern China \\
EOT4 & 8.0 & $32^{\circ} \mathrm{N} 119^{\circ} \mathrm{E}$ & North of the Yangtze River \\
\hline
\end{tabular}

rainfall variability in large areas of north-eastern China with the base point at $\left(42^{\circ} \mathrm{N}, 121^{\circ} \mathrm{E}\right)$. It explains $28.6 \%$ of the total temporal variance (Fig. 2a). EOT2 explains $22.1 \%$ of the total temporal variance, with a peak over the southern lower reaches of the Yangtze valley (Fig. 2b). EOT3 explains $12.4 \%$ of the total temporal variance. It describes a pattern of coherent precipitation variability over southern China with the base point at $\left(24^{\circ} \mathrm{N}, 113^{\circ} \mathrm{E}\right)$ (Fig. 2c). EOT4 peaks over the northern lower reaches of the Yangtze valley. It explains $8 \%$ of the total temporal variance (Fig. 2 d).

As explained in the method Sect. 2.2.2, the EOT pattens in Fig. 2 describe the time variance at all points in the domain. To confirm that the EOT patterns can describe both temporal and spatial variance, we compared the EOT pattern with the map of precipitation anomalies of the same time that the Rx5day occurs in the base points. The 5-day total precipitation anomalies are 5-day total precipitation at the time when Rx5day occurs in the base points in each year relative to the long-term average of 5-day total precipitation at the same dates. By compositing the 5-day accumulated
Fig. 2 Spatial patterns of 4 EOTs of JJA Rx5day related to each EOT base point (pink asterisk), based on the data CN05.1. Numbers in upright are the explained variance of each EOTs to the domain-averaged timeseries, Cross hatches indicate correlations statistically significant at the 5\% level using a two-tailed Student's t-test
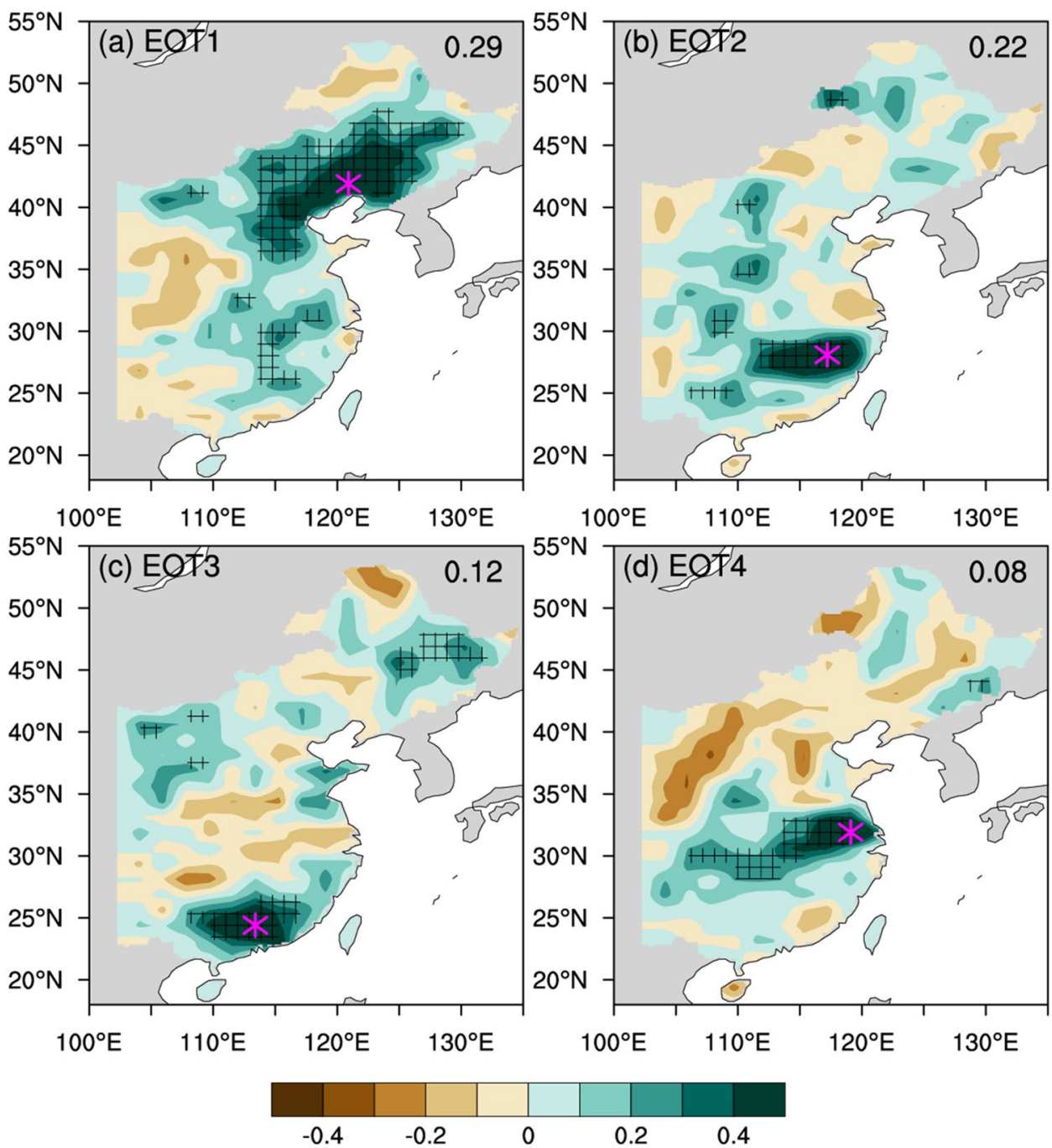
precipitation on the date of Rx5day at the base point of each EOT, we found that the composited precipitation patterns in Fig. 3 are all significantly correlated with EOT patterns in Fig. 2. The pattern correlations with each EOT pattern are $0.72,0.70,0.71$ and 0.71 , respectively, with p-value smaller than 0.05 . These strong correlations imply that the extreme precipitation over each EOT key region varies coherently in space, which would further suggest that the related precipitation patterns are dominated and driven by large-scale processes. Finding the dominant mechanisms that cause extreme precipitation in each key region would improve its prediction.

\subsection{Monsoon front anomalies}

Eastern China summer precipitation is predominantly impacted by a quasi-stationary frontal system, which migrates northward through the summer season. As addressed by Chen (2004), the average lifetime of an individual monsoon frontal event is 8 days, which is very close to the time scale of the Rx5day analysed here. Therefore, we reasonably hypothesize that the band-like Rx5day patterns associated with the leading four EOTs are related to anomalies in the evolution or stationarity of the monsoon front at different phases of the seasonal cycle. To identify the monsoon front, we used the daily meridional gradient of $850-\mathrm{hPa}$ equivalent potential temperature, in a method from Volonté et al. (2021). The climatological monsoon front shows that the monsoon front propagates northward from $25^{\circ} \mathrm{N}$ in June to $40^{\circ} \mathrm{N}$ in August (Fig. 4). The maximum is around $28^{\circ} \mathrm{N}$ in June; it jumps to around $32^{\circ} \mathrm{N}$ in July.

The anomalies in meridional gradient of equivalent potential temperature associated with each EOT are displayed in shading in Fig. 4. In EOT1 the monsoon front is weakened, especially in June and July (Fig. 4a). This is consistent with the EOT-associated Rx5day, which is reduced
Fig. 3 Spatial patterns of composite 5-day total precipitation anomalies $(\mathrm{mm})$ based on the date of Rx5day at each EOT base point (pink asterisk), based on the data CN05.1. The anomalies are relative to long-term mean 5-day total precipitation on the date of Rx5day at each EOT base point. Cross hatches indicate anomalies statistically significant at the $5 \%$ level using a two-tailed Student's t-test
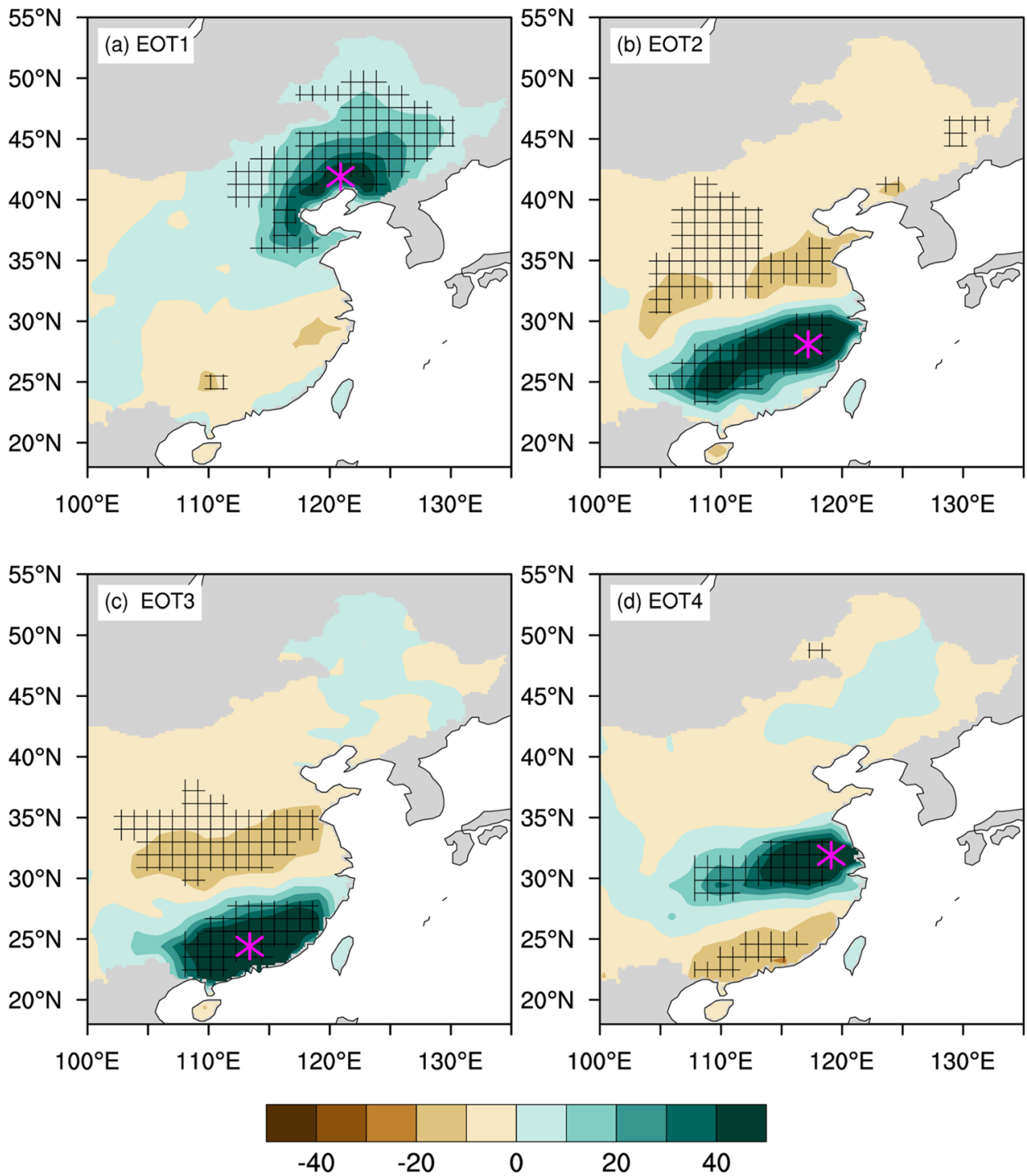

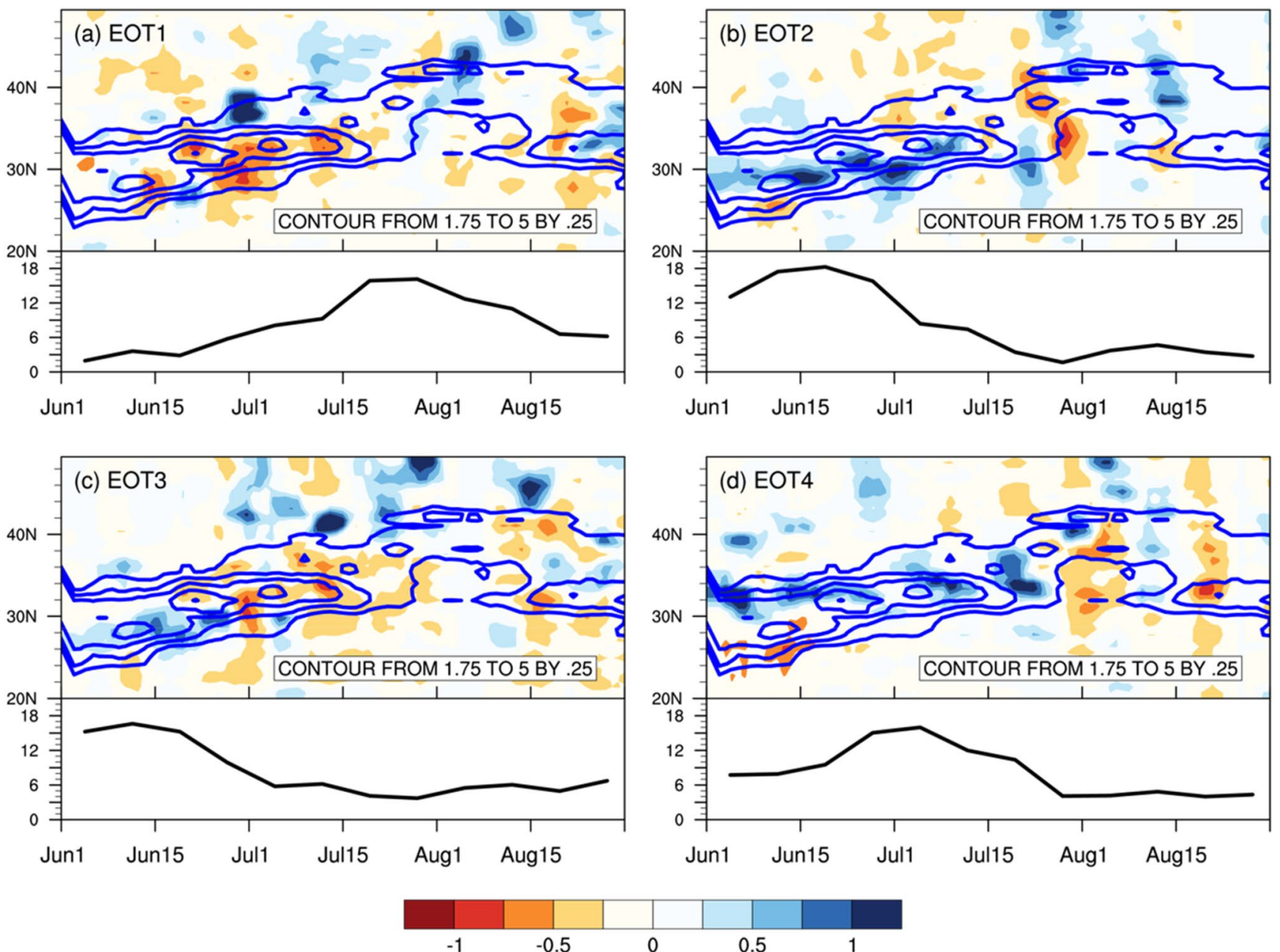

Fig. 4 Seasonal evolutions of variables associated with each EOT: a EOT1, b EOT2, c EOT3, and d EOT4. Contours at top of each panel indicate the climatological seasonal cycle of the zonal mean meridional gradient of equivalent potential temperature at $850 \mathrm{hPa}$ $\left(10^{-6} \mathrm{~K} \mathrm{~m}^{-1}\right)$. Shading in top indicates the seasonal cycle of 5-day meridional gradient anomalies based on the date of Rx5day at each

in the monsoon front region but increased in northern China over region close to the base point at $42^{\circ} \mathrm{N}$ (Fig. 3a). Since the monsoon front is weak in EOT1, the maximum probability of Rx5day events is in the post-Meiyu season, instead of concentrated in the peak of monsoon season (late July-August) (Bottom of Fig. 4a).

Unlike in EOT1, the monsoon fronts in EOTs 2-4 are enhanced, though the enhancement happens at different times of the season and at different latitudes. As shown in Fig. 4b, the monsoon front in EOT2 is enhanced south of $30^{\circ}$ $\mathrm{N}$, with the maximum at $28^{\circ} \mathrm{N}$ in mid-June (Top of Fig. $4 \mathrm{~b}$ ). This is consistent with the distribution of Rx5day in EOT2, which has a maximum over the southern lower reaches of the Yangtze valley (Fig. 3b), and the maximum probability of Rx5day in mid-June coincides with the enhanced monsoon front (bottom in Fig. 4b).
EOT base point. Bottom probability distribution (\%) of 5-day total precipitation anomalies based on the date of Rx5day on each EOT base point in the regions where the correlations with each EOT base point are significant at the $10 \%$ level. The precipitation is from CN05.1 and equivalent potential temperature is calculated based on ERA5

EOT3 is associated with an enhanced monsoon front south of $30^{\circ} \mathrm{N}$ in early June (top of Fig. 4c). This is consistent with higher Rx5day in southern China (Fig. 3c), with the maximum probability in early June (bottom of Fig. 4c). The enhanced monsoon front in EOT4 is north of $30^{\circ} \mathrm{N}$, with a maximum at $34^{\circ} \mathrm{N}$ from June to July. Consistent with the monsoon front anomalies, Rx5day has a maximum over the northern lower reaches of the Yangtze valley (Fig. 4d); the maximum probability is in late June and early July (bottom of Fig. 4d).

The above analysis shows that each Rx5day EOT pattern is related to anomalies in the position and intensity of the monsoon front. Volonté et al. (2021) showed that anomalies of the monsoon front are controlled by large-scale circulations such as the El Niño Southern Oscillation (ENSO), WNPSH and subtropical westerly jet. We will further study 
how these large-scale systems affect each Rx5day pattern via changing the position and intensity of the monsoon front.

\subsection{Moisture budget}

To explore the moisture budget for Rx5day events, we calculated the vertical integrated moisture transport convergence $(M C)$ using daily data. We defined $\delta M C$ as the anomalous MC from its 5-day climatology. Following Tian et al. 2019, $\delta M C$ can be decomposed into anomalies of the dynamic component $(\delta D Y)$, the thermodynamic component $(\delta T H)$, and the covariance between anomalous of humidity and winds $(\delta Q T)$ :

$\delta M C=\delta D Y+\delta T H+\delta Q T$

Here the anomalies related to 5-day climatology in summer are represented by $\delta$, the dynamic component represented by $\delta D Y$ involves only changes in circulation. The thermodynamic contribution represented by $\delta T H$ involves only changes in specific humidity.

Then we composited the $\delta M C$ on the pentad when the base point of each EOT reaches its Rx5day. As shown in Fig. 5a-d, the spatial patterns and magnitudes of the composited $M C$ are similar to those of the composited Rx5day in Fig. 3. This indicates that the four leading Rx5day EOTs are all dominated by the increased moisture transport convergence. For EOT1 and EOT4, the increased MC (Fig. 5a, d) comes mainly from the anomalous circulation $(\delta D Y$, Fig. 5e, h). Anomalies in specific humidity (thermodynamic component, $\delta T H$ ) play an opposing role or a very weak role in the increased Rx5day (Fig. 5i, 1). For EOT 2 and EOT 3, the increased $M C$ (Fig. 5b, c) comes from both $D Y$ (Fig. 5f, g) and $T H$ (Fig. 5j, k), but the increase in $D Y$ is much larger than that in $T H$.

As shown in Figs. 4a and 5a, the anomalous monsoon front associated with EOT1 is very weak. In EOT 2-4 (Figs. $4 \mathrm{~b}-\mathrm{d}, 5 \mathrm{~b}-\mathrm{d}$ ), the anomalous monsoon front is zonally oriented and is consistent with the positive MC anomalies. Since most moisture transport is from the south, the positive $D Y$ components are mainly located to the south of the monsoon front, and the $\mathrm{TH}$ components are located along the monsoon front.

\subsection{The associated circulation}

The above analysis shows that Rx5day variability in summer over eastern China is associated with the strength and position of the monsoon front, which is altered by large scale spatial and temporal circulation variations. Therefore, it is reasonable to assume that Rx5day variability may also be related to large-scale circulation variations. Identifying the connection between the large-scale circulation and Rx5day, and understanding the physical processes involved, are crucial to improve the prediction of the synoptic scale extreme events.

As suggested by Tian et al. (2018), the summer total precipitation variability in China is determined by the largescale circulation variability. We can also use the summer mean circulation to understand the mechanisms of Rx5day, if the interannual variability of Rx5day is correlated to summer total precipitation variability. To reveal the relationship between summer total precipitation and extreme precipitation variations, we regressed the summer total precipitation on the timeseries of the leading EOTs. The resulting regression maps (Fig. 6) show that the regressed total precipitation patterns are significantly correlated with the respective EOT patterns, with the pattern correlations of $0.31,0.70,0.75$ and 0.69 , respectively.

We also projected the summer total precipitation on the spatial patterns of the leading four EOTs (red lines in Fig. 7). All four timeseries of regression coefficients have significant positive correlations with the leading four EOT timeseries (black lines in Fig. 7). This indicates that the summer mean precipitation and Rx5day interannual variations are highly correlated in time and space.

Thus, we employ the summer mean circulation anomalies to explain the mechanisms related to Rx5day variability. The large-scale circulation patterns related to each EOTs are produced by regressing the summer mean sea surface temperature, sea level pressure, 850 -hPa horizontal wind, $500-\mathrm{hPa}$ geopotential height and $200-\mathrm{hPa}$ zonal wind onto the time series of the four leading EOT patterns.

\subsubsection{EOT1}

Positive EOT1 (Fig. 8a) is associated with an anomalous southerly wind from the South China Sea across eastern China, transporting water vapor to north-eastern China. Additionally, there is a cyclonic wind anomaly over northeastern China, which increases the low-level convergence of moisture transported from the Western North Pacific. This is consistent with higher Rx5day over north-eastern China in EOT1 (Fig. 3a). The southerly and the cyclonic wind anomalies might be related to the East Asian uppertropospheric jet stream (EAJS). As shown in Fig. 8b, the westerly wind at $200 \mathrm{hPa}$ is enhanced north of $45^{\circ} \mathrm{N}$ and is suppressed south of $45^{\circ} \mathrm{N}$. This dipole pattern indicates a northward shift of the EAJS. The anti-cyclonic sheer of wind anomalies supports an upper-tropospheric divergence anomaly (Fig. 8b). As revealed in Xuan et al. (2011), the upperlevel divergence of air flow is associated with an equivalent barotropic structure, which favours ascending motion below it. The ascending motion favours lower SLP and increased rainfall over north-eastern China (Fig. 8a). The lower SLP over land increases the land-sea pressure gradients and 

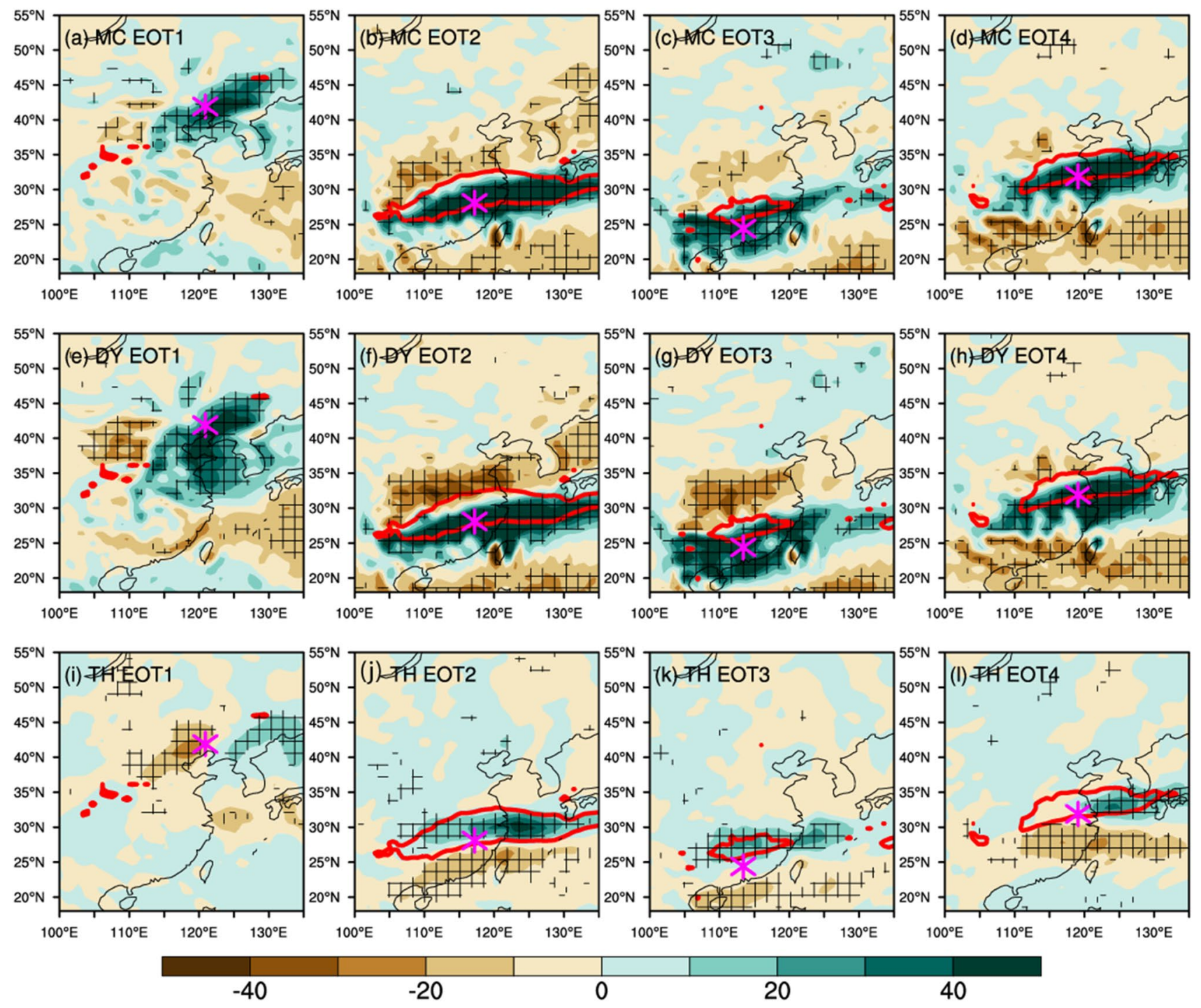

Fig. 5 Spatial patterns of anomalous 5-day total moisture transport convergence (MC, a-d, mm), it's dynamic component (DY, e-h, $\mathrm{mm}$ ) and its thermodynamic component $(\mathrm{TH}, \mathbf{i}-\mathbf{l}, \mathbf{m m})$ based on the date of Rx5day at each EOT base point (pink asterisk). Cross hatches indicate anomalies statistically significant at the 5\% level using a twotailed Student's t-test. Red lines indicate anomalies of composited 5-day mean meridional gradient of $850 \mathrm{hPa}$ equivalent potential temperature $\left(4 \times 10^{-6} \mathrm{~K} \mathrm{~m}^{-1}\right)$ enhances the southerly wind anomalies along the east coast of China, which contributes to Rx5day over north-eastern China. Strong associations between the EAJS and the eastern China monsoon rainfall have been found by many previous studies. $\mathrm{Lu}$ (2004) revealed that the meridional displacement of the EAJS has a close relationship to the EASM rainfall. The northward movement of EAJS results in more precipitation over northern China (Gong and Ho 2002). Lin (2013) also showed that when the westerly wind is enhanced north of the EAJS axis, rainfall significantly increases in northeast China and decreases in the Yellow River-Huaihe River valleys. The previous studies showed that the northward shift of EAJS is related to the negative anomalies of South Asian high and WNPSH (Lin and Lu 2005) and the preceding SST in the extratropical North Pacific SST (Xuan et al. 2011). However, more details about the formation and position of EAJS remain an interesting future research topic.

\subsubsection{EOT2 and EOT4}

The circulation anomalies associated with positive EOT2 and EOT4 are illustrated in Fig. 9a, b, respectively. They show that the WNPSH is enhanced, and its western ridge extends to southern China, pushing warm and wet air northward and blocking high-latitude cold air. The westward extended WNPSH develops and enhances the monsoon front as shown in Fig. 4b, d. Besides the similarity, the anomalies of WNPSH also show differences in EOT2 and EOT4. 
Fig. 6 Regression maps of simultaneous JJA total precipitation (TP, $\mathrm{mm}$ ) onto the normalized time series of EOT1 (a), EOT2 (b), EOT3 (c) and EOT4 (d). Summer total precipitation is from ERA5. Cross Hatches indicate correlations of $\mathrm{TP}$ and normalized time series of EOTs that are statistically significant at the $5 \%$ level using a two-tailed Student's t-test
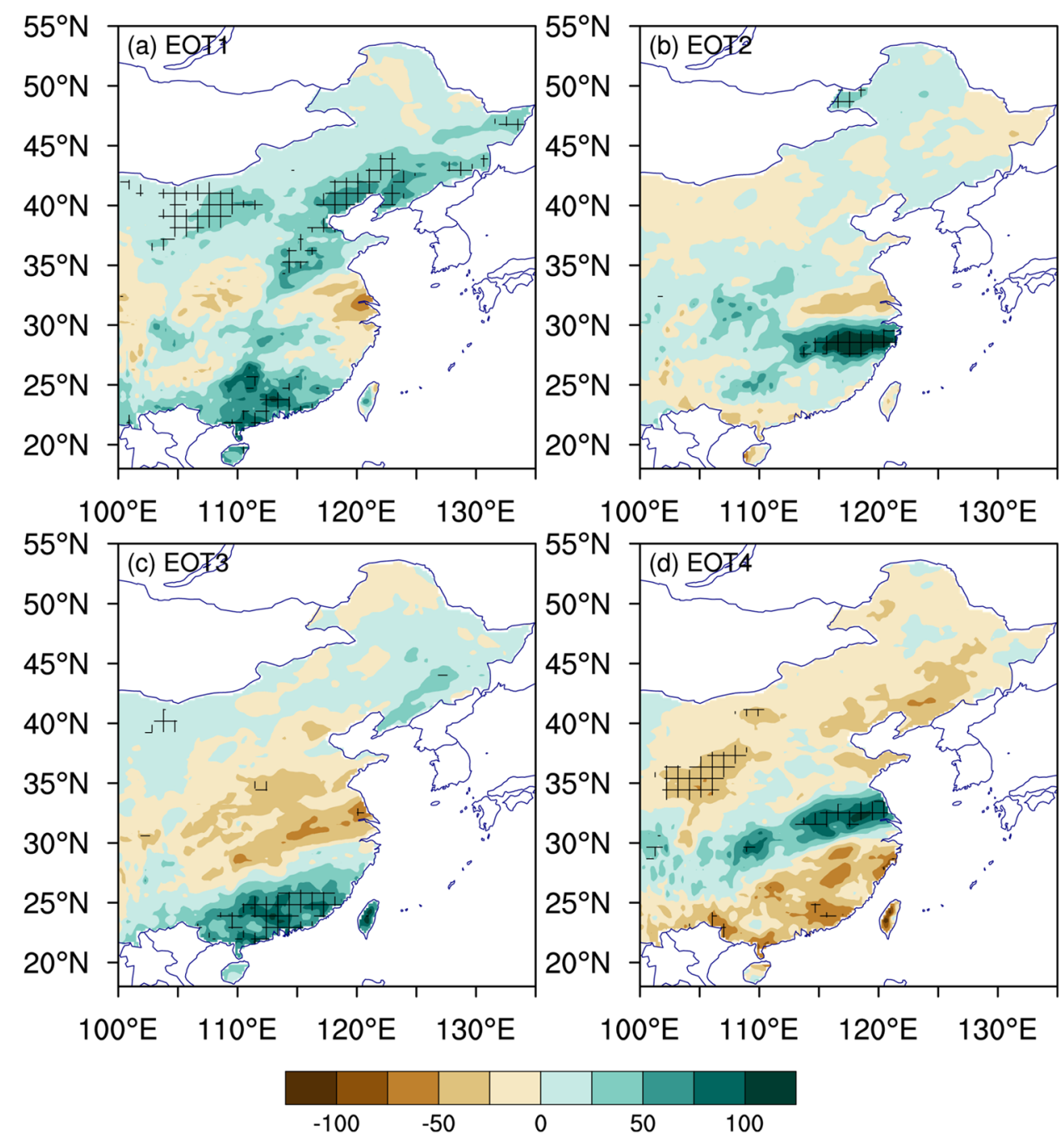

In EOT2, the enhanced WNPSH is weaker than in EOT4. The southerly wind around the western ridge reaches the southern Yangtze valley around $28^{\circ} \mathrm{N}$. This enhances the quasi-stationary monsoon front in the southern Yangtze valley with more extreme precipitation along $28^{\circ} \mathrm{N}$.

The enhanced and westward extended WNPSH associated with EOT2 and EOT4 is related to an El Niño decaying phase. The connection from ENSO to EOT2 and EOT4 is shown by regression fields of SST, SLP and 850-hPa horizontal wind on the EOT timeseries (Fig. 9c-h). The regression maps of SST in DJF, MAM and JJA for EOT2 (Fig. 9c, e, g) and EOT4 (Fig. 9d, f, h) produce similar patterns of decaying El Niño. This indicates that Rx5day variations over the south or north of the lower reaches of Yangtze River valley are preceded by an El Niño-like SST anomaly in the previous winter. The warm anomalies of SST in the eastern tropical Pacific decay in the following spring and summer. As explained by Stuecker et al. (2013, 2015), in the El Niño decaying phase the western North Pacific subtropical high is enhanced and extends further west from the previous winter to the following summer, resulting in an $850-\mathrm{hPa}$ anomalous anticyclonic circulation near the southeast coast of China in spring and summer. This anomalous anticyclonic circulation enhances the pressure gradient to its northwest, resulting in a more intense and stable monsoon front, which increases the possibility of extreme precipitation along the monsoon front. The differences in the WNPSH associated with EOT2 and EOT4 are related to the different El Niño amplitudes in the previous winter.

The SST anomalies associated with EOT4 (Fig. 9d, f, h) are stronger than those for EOT2 (Fig. 9c, e, g), followed by a stronger WNPSH in JJA. Additionally, these SST anomalies reach a maximum in previous winter and decay in summer. In El Niño decay year, the associated easterly anomalies in the Indian ocean weaken the climatological monsoon westerlies, reducing surface evaporation and increasing SST in Indian ocean. As shown in Fig. 9g, h, the stronger El Niño in previous winter associated with EOT4 (Fig. 9h) is related to stronger easterly wind anomalies than in EOT2 (Fig. 9g) and thus the warm SST anomalies over the Indian Ocean are 


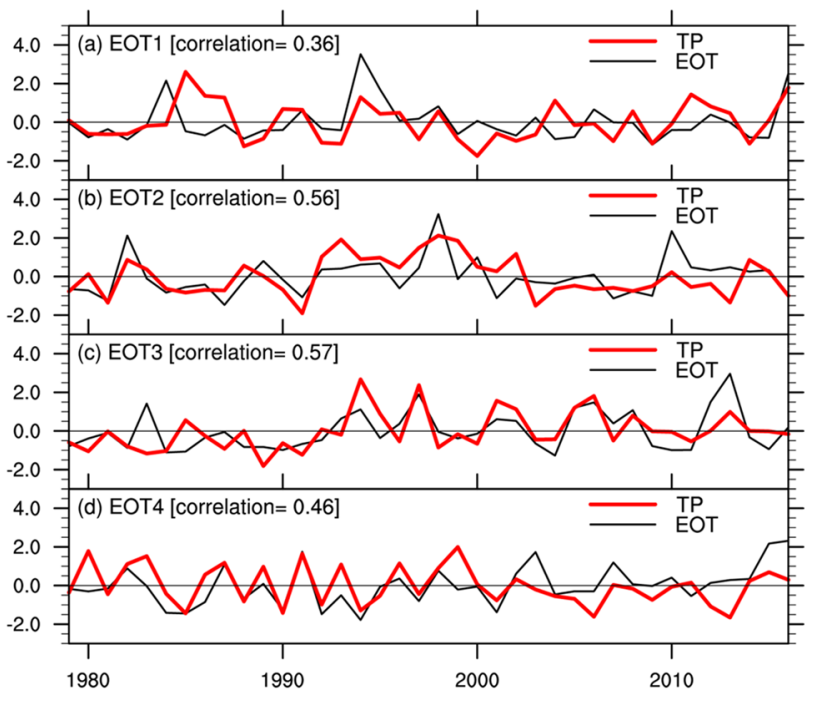

Fig. 7 Normalized time series of projection coefficient of summer total precipitation (TP) to the EOT patterns (red) and the normalized EOT time series (black). The correlations between the two timeseries in each panel (shown at top left of each panel) are significant at the $5 \%$ level using a two-tailed Student's t-test

stronger for EOT4 than for EOT2. As suggested by Xie and Zhou (2017), warm Indian Ocean SST anomalies can generate a local cyclonic anomaly, with easterly anomalies over the Maritime Continent, and further enhance the WNPSH. The Indian Ocean warming can also force the Pacific-Japan (PJ) pattern via a tropospheric Kelvin wave. The enhanced PJ pattern is related to an anti-cyclonic anomaly and enhanced WNPSH around $10^{\circ}-25^{\circ} \mathrm{N}$. This is consistent with the previous study (Kosaka et al. 2013) which shows that the amplitude PJ pattern is correlated with the Niño3.4 index in the preceding boreal winter. Therefore, because of a stronger $\mathrm{El}$ Niño in the previous winter and warmer Indian Ocean SST in the previous spring, the WNPSH associated with EOT4 is stronger than that associated with EOT2. The stronger WNPSH pushes the monsoon front further north. Thus, the Rx5day anomalies associated with EOT4 are mainly north of the lower reaches of the Yangtze valley; the extreme precipitation anomalies of EOT2 are mainly south of the lower reaches of the Yangtze valley.

\subsubsection{EOT3}

The WNPSH associated with EOT3 is enhanced, with an anomalous anticyclonic circulation to the east coast of southern China (Fig. 10a). The anomalous south-easterly wind on the western edge of the high SLP anomalies transports more water vapor to southern China and feeds the convection along the monsoon front (Fig. $5 \mathrm{~g}$ ), leading to higher Rx5day in southern China (Fig. 3c).

The enhanced WNPSH in Fig. 10a coincides with a negative SLP anomaly north at $40^{\circ} \mathrm{N}$, and a positive SLP anomaly at $55^{\circ} \mathrm{N}$. This north-south sea-saw pattern of SLP anomalies resembles the Pacific-Japan (PJ) pattern that features high, low, and high SLP anomalies in the tropical, middle and extratropical WNP, respectively, as shown in Huang and Sun (1992), Kubota et al. (2016) and Wang (2019). Consistent with Kosaka and Nakamura (2006), the PJ pattern, a north-westward propagating Rossby wave, is triggered by the intensified convection and the convective heating over the Maritime Continent (Fig. 10b). The regression maps related to EOT3 show that the intensified convection is consistent with anomalous divergence at $200 \mathrm{hPa}$ (Fig. 10b) and is associated with the El Niño-like warm SST anomalies (Fig. 10d). Note that the SST anomalies over the tropical east Pacific related to EOT3 are weak in the previous winter, but they develop in spring, intensify in summer and maintain in autumn, indicating EOT3 being associated with developing phase of El Nino (not shown here).

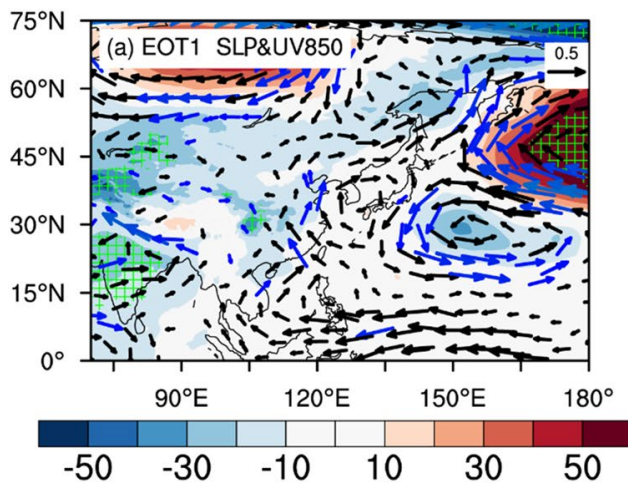

Fig. 8 a Regression maps of JJA sea level pressure (SLP, Pa, shaded), and $850 \mathrm{hPa}$ wind $\left(\mathrm{m} \mathrm{s}^{-1}\right.$,vector) onto the normalized time series of EOT1, b as in (a) but for regressions of JJA $500 \mathrm{hPa}$ geopotential height ( $\mathrm{m}$, contours) and $200 \mathrm{hPa}$ zonal wind ( $\mathrm{m} \mathrm{s}^{-1}$, shaded).

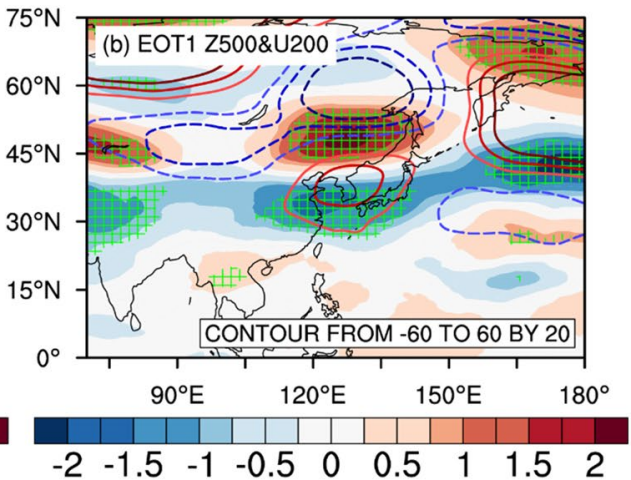

Hatches indicate the correlations of SLP in (a) and zonal wind in (b) with the EOT timeseries are significant at the 5\% level. Blue wind vectors indicate that at least one component of the horizontal wind vector is significant at the $5 \%$ level 


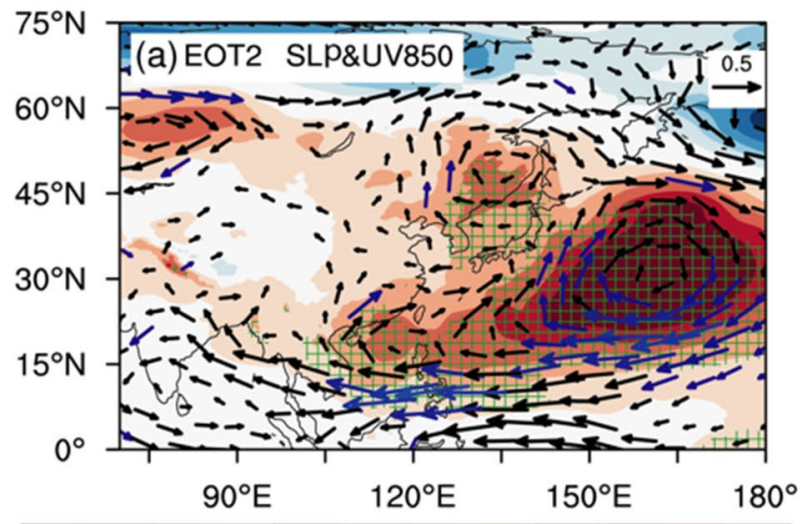

\begin{tabular}{ll|l|l|l|l|}
\hline-50 & -30 & -10 & 10 & 30 & 50
\end{tabular}
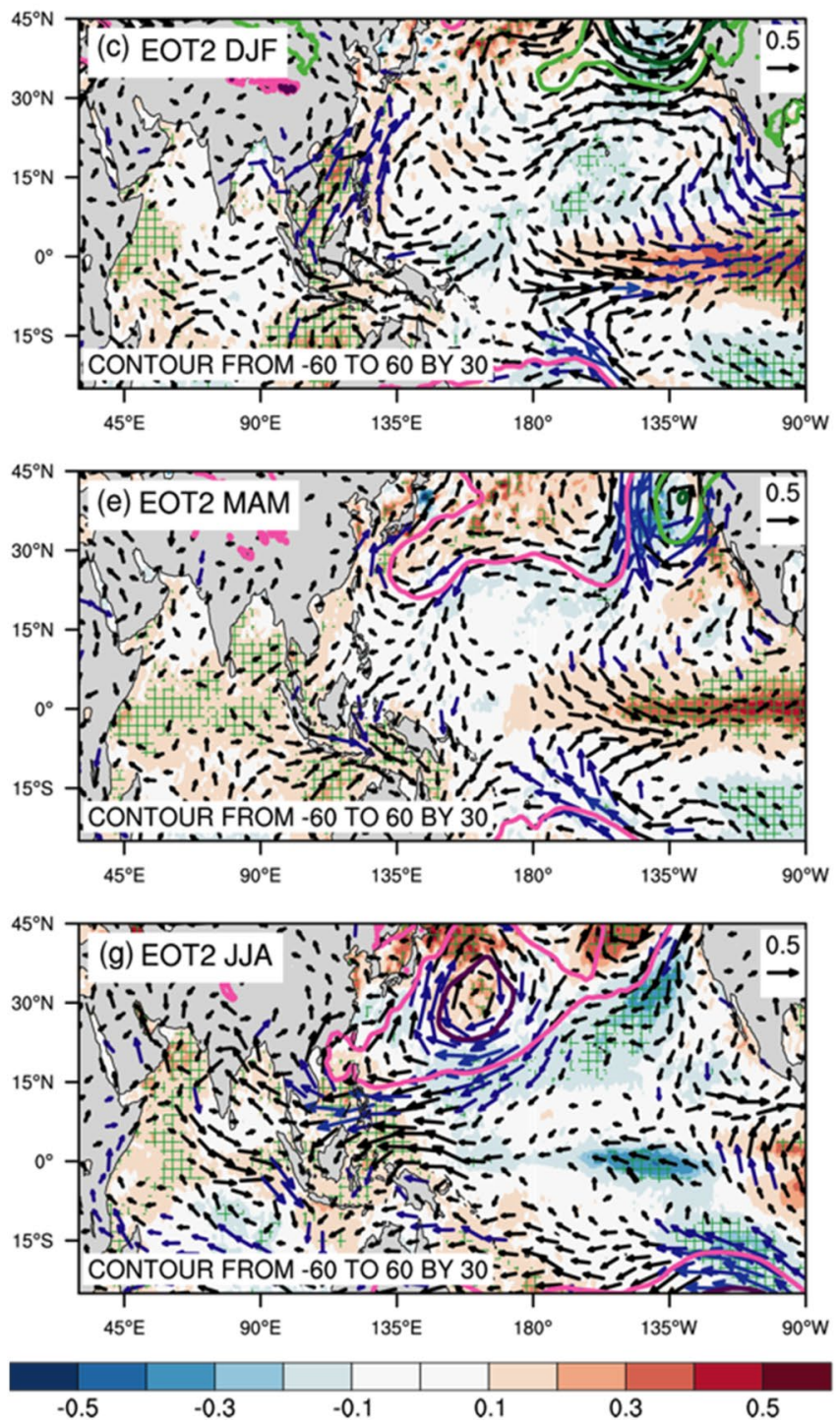

Fig. 9 a, b Regression maps of JJA sea level pressure (SLP, Pa, shaded), and $850 \mathrm{hPa}$ wind ( $\mathrm{ms}^{-1}$, vector) onto the normalized time series of EOT2 and EOT4. $\mathbf{c}-\mathbf{h}$ as in $(\mathbf{a}, \mathbf{b})$ but for regression maps of previous DJF, MAM and simultaneous JJA sea surface temperature (SST, K, shaded), SLP (hPa, contours), and $850 \mathrm{hPa}$ wind (ms ${ }^{-1}$, vec-
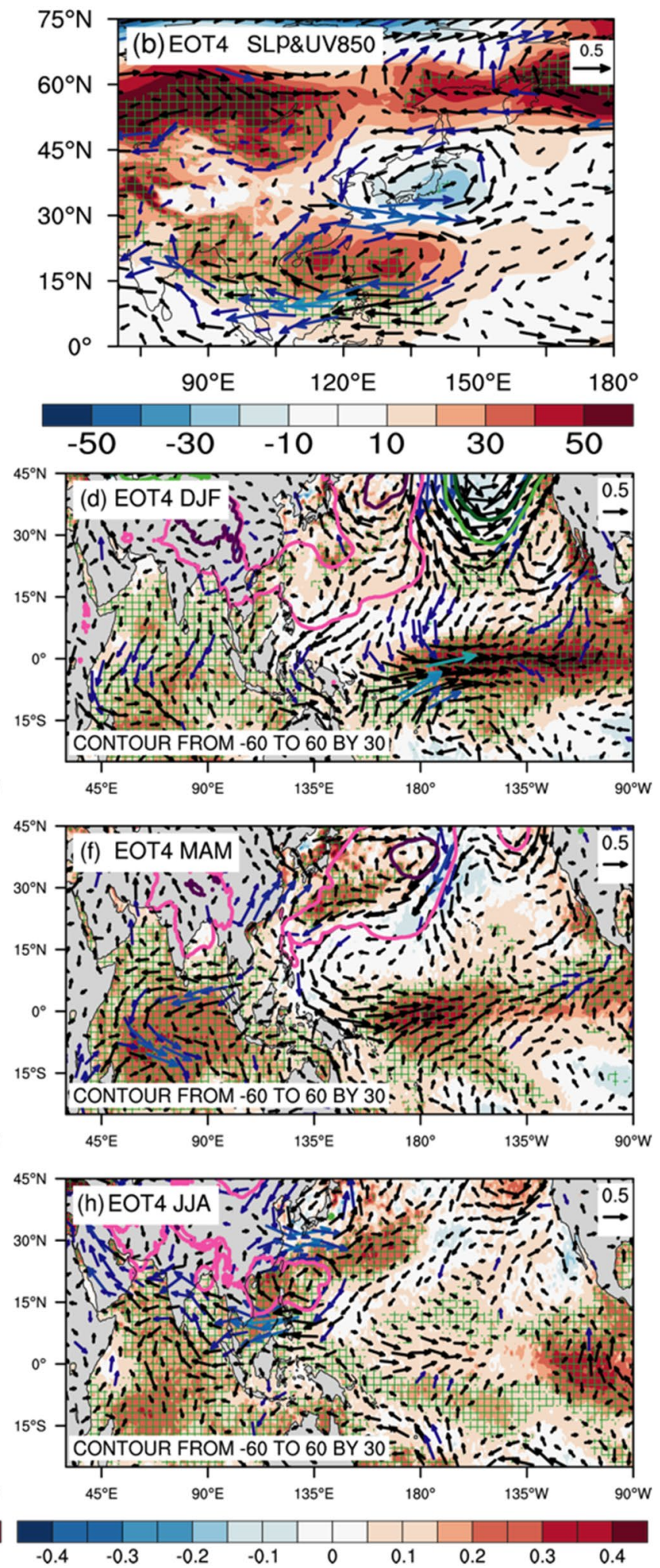

tor) onto the normalized time series of EOT2 (left) and EOT4 (right). Hatches indicate correlations of SST with EOT2 or EOT4 are significant at the 5\% level. Blue vectors indicate that at least one component of the horizontal wind vector is significant at the $5 \%$ level. Vectors are omitted for magnitude $<0.1 \mathrm{~ms}^{-1}$ 

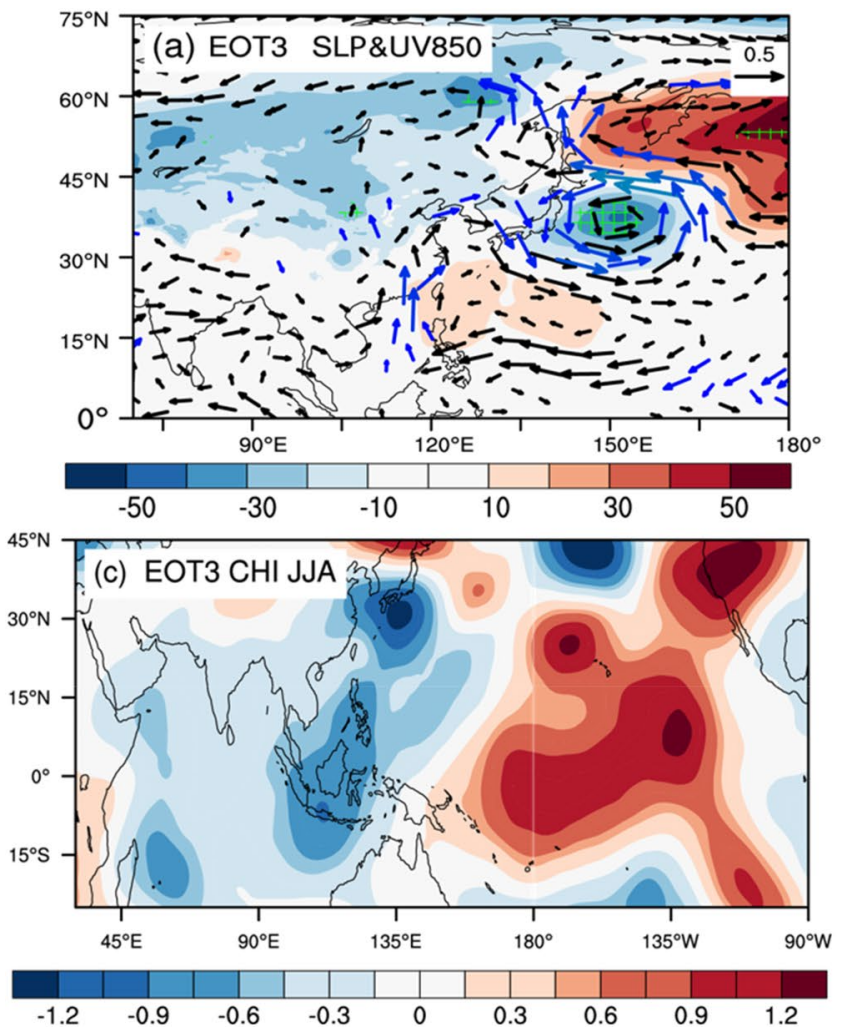

Fig. 10 a Regression maps of JJA sea level pressure (SLP, Pa, shaded), and $850 \mathrm{hPa}$ wind ( $\mathrm{ms}^{-1}$, vector) onto the normalized time series of EOT3. b-d As in (a) but for regression maps of (b) Outgoing longwave radiation $\left(\mathrm{W} / \mathrm{m}^{2}\right)$, c $200 \mathrm{hPa}$ velocity potential $\left(10^{6}\right.$

\section{SOM regimes of extreme rainfall and circulation}

By comparing the SOMs results to the EOT-based results, we can ascertain agreement on patterns of extreme precipitation variability, as well as on the associated circulation patterns.

Prior to applying SOM analysis, the anomalies of consecutive 5-day data (precipitation and atmospheric circulation) at each grid point are calculated by subtracting the 5-day climatology for 1981-2010. We first apply the SOM technique to the precipitation anomaly data to determine the variability of summer season (JJA) precipitation for 1960-2016 over Eastern China (in the same manner as used in the EOT analysis). We then apply composite analysis techniques to explain the precipitation variability in the context of anomalous atmospheric circulations.

As mentioned in Sect. 2.2.3, we tested various node configurations, including 3 by 2, 4 by 3,5 by 4,6 by 5,7 by 6,8 by 7 and 9 by 8 , with node-to-node dissimilarity, node-to-data similarity, and quantization error not changing significantly beyond the 5 by 4 node configuration. Hence a 5 by 4 node configuration is retained, which has
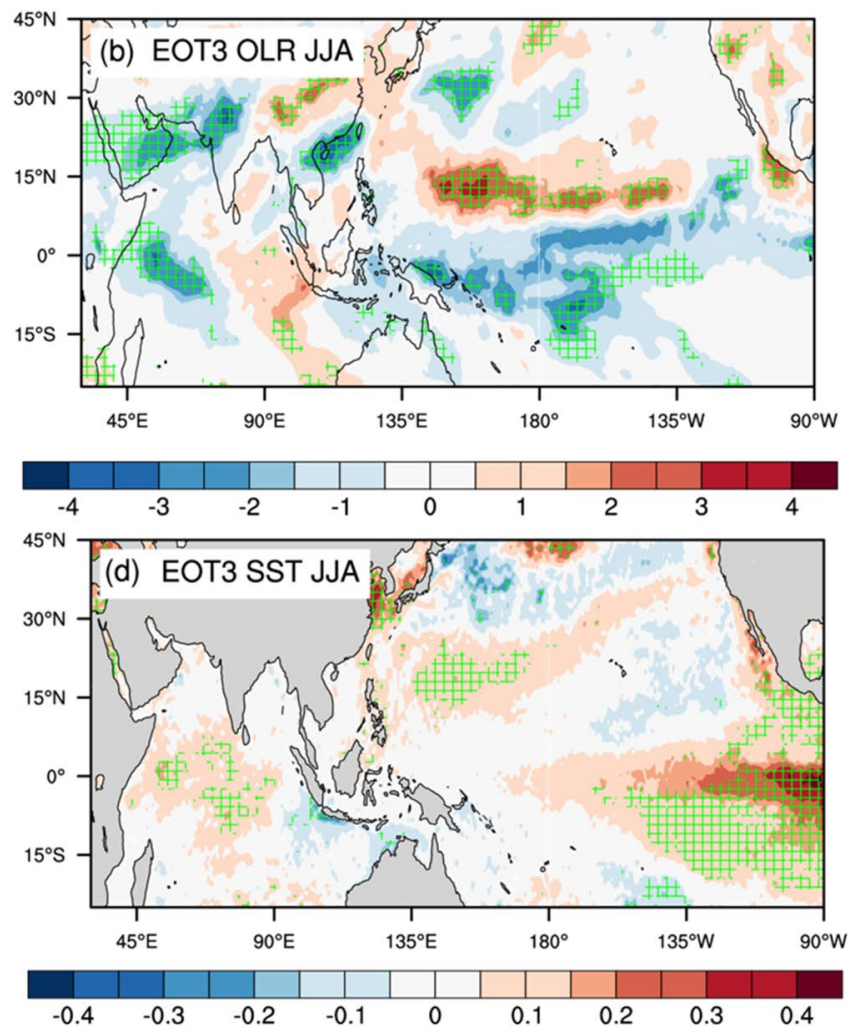

$\left.\mathrm{m}^{2} \mathrm{~s}^{-1}\right)$, and $\mathbf{d}$ sea surface temperature (K). Shading indicates correlations with normalized time series of EOT3 are significant at the $5 \%$ level

also been shown to be a proper compromise between a reasonable representation of the pattern variability and the ease of visual interpretation, in a previous study on summer precipitation regions in Eastern China (Zhou et al. 2020).

As shown in Fig. 11, some SOM node patterns (e.g., P9, P10, P13 and P14) resemble EOT1, with an anomalous high precipitation centre over north-eastern China. Other SOM node patterns (e.g., P2, P3, and P4) resemble EOT2, with an anomalous high precipitation centre over the south of the lower reaches of the Yangtze valley. Still other SOM node patterns (e.g., P1 and P5) resemble EOT3, with an anomalous high precipitation centre over South China. Finally, several SOM node patterns (e.g., P12, P16 and P20) resemble EOT4, with an anomalous high precipitation centre over the northern lower reaches of the Yangtze valley. Applying the SOM technique also identifies some intermediary patterns in which the anomalous precipitation high and low centres are not as extreme (e.g., P6, P7, P11, P14, P18), as well as patterns not identified in the EOT analysis, (e.g., P17, with an overall low precipitation anomaly over South China) also emerges from applying SOMs. 

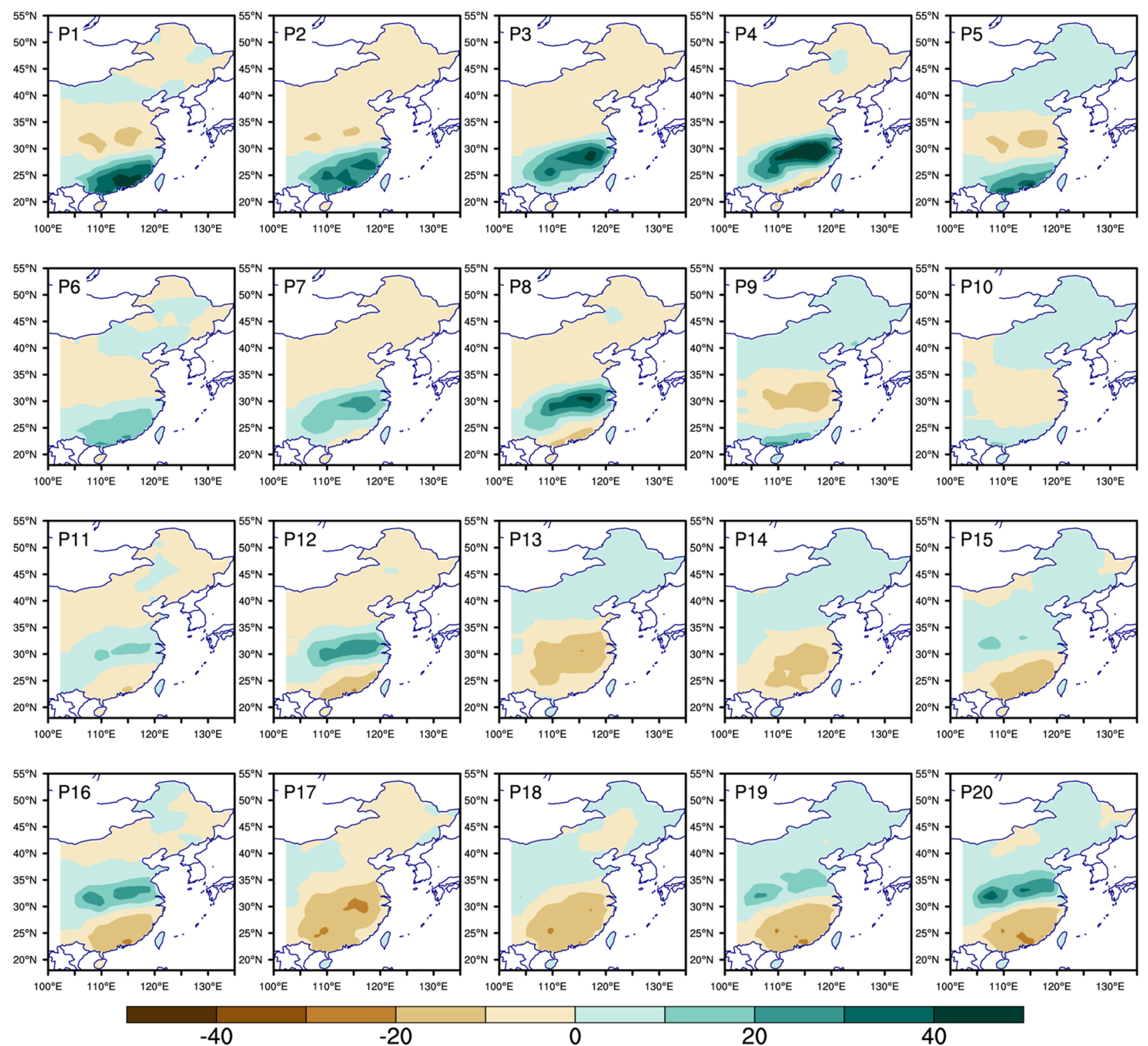

Fig. 11 The consecutive 5-day anomalies of the 5 by 4 nodes derived from summer precipitation ( $\mathrm{mm}$ ) over Eastern China during 19792016 (w.r.t. 1981-2010). 1979-2016 is shown here to be consistent

To further align the two lines of analysis (SOMs and EOTs), we clustered the SOM node patterns into four patterns according to their similarity to the top four EOTs (as discussed in the previous paragraph), ignoring the intermediary patterns (Fig. 12).

Composite analysis is performed on the consecutive 5-day anomalies of summer precipitation associated with the SOM nodes (those most closely resemble different EOT patterns, same as done for Fig. 12). This reveals that by applying the SOM technique, we can detect similar spatial precipitation patterns as for the EOTs, with high anomalous precipitation peaks in north-eastern China, the south of the lower with the data availability of the following circulation analysis. The different SOM node patterns are denoted in the upper left corner of each panel

reaches of the Yangtze valley, South China, and the north of lower reaches of the Yangtze valley, as shown in Fig. 12. The summer precipitation patterns are all significantly correlated with the EOTs, with the pattern correlations of $0.33,0.57$, 0.71 and 0.45 , respectively.

Composite analysis of the associated circulations in Fig. 13 shows that, like the EOT results, the circulation anomalies associated with patterns 2 (Fig. 13b) and 4 (Fig. 13d) both show an enhanced WNPSH, but the enhanced WNPSH in pattern 2 is weaker than that in pattern 4 . The WNPSH in pattern 3 (Fig. 13c) is also slightly enhanced, but the enhancement is weaker than for patterns 2 
Fig. 12 Composite consecutive 5-day anomalies of summer precipitation $(\mathrm{mm})$ over Eastern China during 1979-2016 (w.r.t. 1981-2010), using all the days that are associated with the SOM nodes that most closely resemble EOTs 1, 2, 3 and 4. The closest EOT pattern number is denoted in the top left of each panel
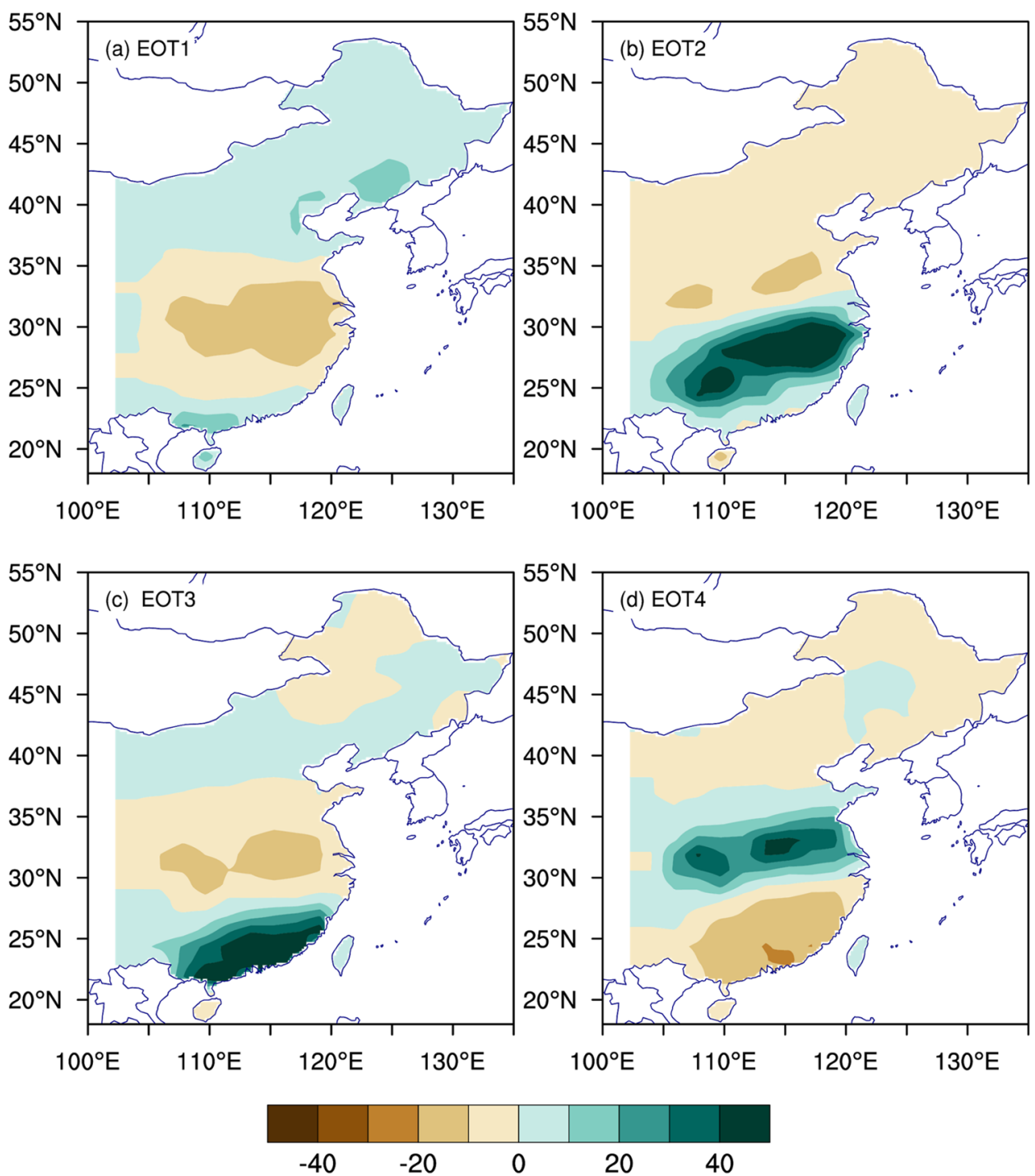

and 4, and the centre is further east. As for pattern 1, we also find a northward-displaced jet, indicated by an anomalous upper level (250 hPa) zonal wind (results not shown here).

Overall, it is encouraging to see that using two different methods-SOMs treat the data as a continuum rather than discretized, whereas EOTs rely on eigenfunction analysis and are orthogonal in time-we can find similar precipitation patterns, as well as similar associated circulation patterns. This indicates that the identified four key regions of extreme precipitation and the related mechanisms are robust, as they are not sensitive to the choice of method.

\section{Summary}

This work identified the key regions of eastern China summer maximum 5-day precipitation interannual variability by using the Empirical Orthogonal Teleconnection (EOT;
Smith 2004); van den Dool et al. 2000) technique, and then identified the water vapor transport processes and circulations that fuel those precipitation events. To confirm that the key regions and the related mechanisms are not dependant on the EOT method, these EOT-based circulation regimes are further validated by comparing them to results derived from applying Self-Organising Maps (SOMs; Kohonen (2001); Liu and Weisberg (2011)) of regional circulation. The main results are as follows:

(1) Using the EOT analysis, we identified 4 key regions of coherent interannual variability in maximum 5-day precipitation in eastern China: north-eastern China (EOT1), the south of the lower reaches of the Yangtze valley (EOT2), the north of the lower reaches of the Yangtze valley (EOT4) and southern China (EOT3). We also found that within each region, the extreme precipitation tends to occur simultaneously. 

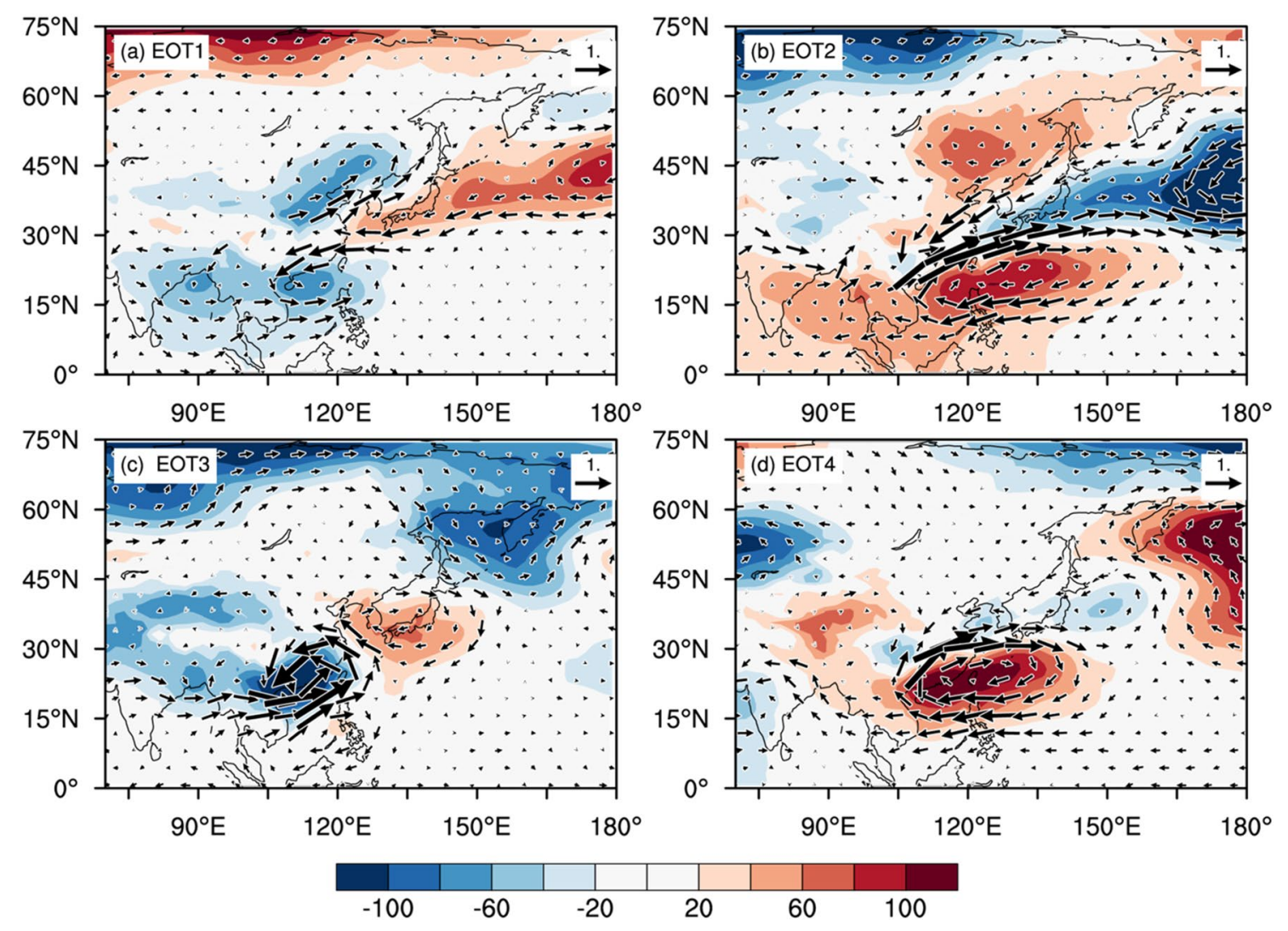

Fig. 13 Composite consecutive 5-day anomalies of mean sea level pressure (Pa, shown as shading), and $850-\mathrm{hPa}$ horizontal winds $\left(\mathrm{ms}^{-1}\right.$ shown as vectors) during 1979-2016 (w.r.t. 1981-2010), using all the

days associated with the SOM nodes that most closely resemble EOT 1, 23 and 4. The 5-day averaged values are shown here. The closest EOT pattern number is denoted in the top left of each panel

(2) The key region of EOT1 is in north-eastern China. A strong EASM with a weak monsoon front and a northward displaced upper-tropospheric westerly jet enhance the extreme precipitation related to EOT1.

(3) The key regions related to EOT2 and EOT4 are the south and north of the lower reaches of the Yangtze valley, respectively. The extreme precipitations over these two regions are related to a strong and stable monsoon front. The monsoon fronts are enhanced and kept stable over the south or north of the lower reaches of the Yangtze valley by the enhanced and westward extended WNPSH.

(4) The anomalies of WNPSH related to EOT2 and EOT4 are related to the El Niño decaying phase. In EOT4, the El Niño shaped SST warming in the tropical eastern Pacific is stronger, followed by a stronger WNPSH, pushing the monsoon front to the north of the lower reaches of the Yangtze River.

(5) The WNPSH in EOT3 is also enhanced. The anomalous southerly wind around the western ridge of WNPSH transports more warm and wet air to southern China and leads to increased precipitation there. The enhancement of WNPSH in EOT3 is related to Pacific-Japan

pattern, which is triggered by the enhanced convective heating over the Maritime Continent.

(6) The 4 key regions of Rx5day and related circulation anomalies are not dependent on the EOT method we use, as they are confirmed with the Self-Organising Maps (SOMs) technique, which finds similar precipitation patterns and similar associated circulation patterns.

The dominant modes of interannual variability in extreme precipitation and the driving mechanisms identified in this study could provide insights toward developing an early warning system and improve future projections of extreme precipitation in eastern China. Since we still rely on global climate models to make future projections, now a question arises: How well can global models reproduce the observed extreme precipitation variability over eastern China and associated physical processes? Therefore, we also aim to evaluate how current climate models can reproduce these signals and what changes in risk they forecast. This will be presented in Part II of this study (Freychet et al. 2021). 
Acknowledgements This work and its contributors were supported by the UK-China Research and Innovation Partnership Fund through the Met Office Climate Science for Service Partnership (CSSP) China EERCH project as part of the Newton Fund. BD is supported by the U.K. National Centre for Atmospheric Science (NCAS) at the University of Reading. NPK was also supported by the ACREW programme of NCAS, part of the Global Challenges Research Fund (GCRF) administered by the Natural Environment Research Council. The authors would like to thank anonymous reviewers for their constructive comments on the earlier version of the paper.

Funding This work was funded by newton fund (Grant no. H5480000).

Open Access This article is licensed under a Creative Commons Attribution 4.0 International License, which permits use, sharing, adaptation, distribution and reproduction in any medium or format, as long as you give appropriate credit to the original author(s) and the source, provide a link to the Creative Commons licence, and indicate if changes were made. The images or other third party material in this article are included in the article's Creative Commons licence, unless indicated otherwise in a credit line to the material. If material is not included in the article's Creative Commons licence and your intended use is not permitted by statutory regulation or exceeds the permitted use, you will need to obtain permission directly from the copyright holder. To view a copy of this licence, visit http://creativecommons.org/licenses/by/4.0/.

\section{References}

Chang CP, Zhang Y, Li T (2000a) Interannual and interdecadal variations of the East Asian summer monsoon and tropical Pacific SSTs. Part I: Roles of the subtropical ridge. J Clim 13(24):4310-4325

Chang CP, Zhang Y, Li T (2000b) Interannual and interdecadal variations of the East Asian summer monsoon and tropical Pacific SSTs. Part II: meridional structure of the monsoon. J Clim 13(24):4326-4340

Chen GTJ (2004) Research on the phenomena of Meiyu during the past quarter century: an overview. In: Chang CP (ed) The East Asian monsoon. World Scientific, Singapore, pp 357-403

Chen X, Zhou T (2017) Surface air temperature projection under $1.5^{\circ} \mathrm{C}$ warming threshold based on corrected pattern scaling technique. Adv Earth Sci 32(4):435-445

Ding Y (2004) Seasonal march of the East-Asian summer monsoon. East Asian Monsoon 3-53

Ding Y, Chan JC (2005) The East Asian summer monsoon: an overview. Meteorol Atmos Phys 89(1-4):117-142

Freychet et al (2021) Physical processes of summer extreme rainfall interannual variability in Eastern China. Part II: evaluation of CMIP6 models. Clim Dyn (Accepted)

Gong DY, Ho CH (2002) Shift in the summer rainfall over the Yangtze River valley in the late 1970s. Geophys Res Lett 29(10):78-81

Guo X, Huang J, Luo Y, Zhao Z, Xu Y (2016) Projection of precipitation extremes for eight global warming targets by 17 CMIP5 models. Nat Hazards 84(3):2299-2319

Hersbach H, Bell B, Berrisford P, Hirahara S, Horányi A, MuñozSabater J et al. (2020) The ERA5 global reanalysis. Q J R Meteorol Soc 146(730):1999-2049

Hong X, Lu R (2016) The meridional displacement of the summer Asian jet, Silk Road pattern, and tropical SST anomalies. J Clim 29(10):3753-3766
Huang R, Sun F (1992) Impacts of the tropical western Pacific on the East Asian summer monsoon. J Meteorol Soc Jpn Ser II 70(1B):243-256

Hubacek K, Guan D, Barua A (2007) Changing lifestyles and consumption patterns in developing countries: a scenario analysis for China and India. Futures 39(9):1084-1096

Kitoh A, Endo H, Krishna Kumar K, Cavalcanti IF, Goswami P, Zhou $\mathrm{T}$ (2013) Monsoons in a changing world: a regional perspective in a global context. J Geophys Res Atmos 118(8):3053-3065

Kohonen T (2001) Learning vector quantization. In: Self-organizing maps. Springer, Berlin, Heidelberg, pp 245-261

Kosaka Y, Nakamura H (2006) Structure and dynamics of the summertime Pacific-Japan teleconnection pattern. Q J R Meteorol Soc 132(619):2009-2030

Kosaka Y, Xie SP, Lau NC, Vecchi GA (2013) Origin of seasonal predictability for summer climate over the Northwestern Pacific. Proc Natl Acad Sci USA 110:7574-7579. https://doi.org/10.1073/ pnas. 1215582110

Kubota H, Kosaka Y, Xie SP (2016) A 117-yearlong index of the Pacific-Japan pattern with application to interdecadal variability. Int J Climatol 36(4):1575-1589

Lennard C, Hegerl G (2014) Relating changes in synoptic circulation to the surface rainfall response using self-organizing maps. Clim Dyn 44(3-4):861-879. https://doi.org/10.1007/s00382-014-2169-6

Li D, Zou L, Zhou T (2017) Changes of extreme indices over China in response to $1.5^{\circ} \mathrm{C}$ global warming projected by a regional climate model. Adv Earth Sci 32(4):446-457

Lin Z (2013) Impacts of two types of northward jumps of the East Asian upper-tropospheric jet stream in midsummer on rainfall in eastern China. Adv Atmos Sci 30(4):1224-1234

Lin Z, Lu R (2005) Interannual meridional displacement of the East Asian upper-tropospheric jet stream in summer. Adv Atmos Sci 22(2):199-211

Liu Y, Weisberg RH (2011) A review of self-organizing map applications in meteorology and oceanography. In: Self-organizing maps: applications and novel algorithm design, vol 1, pp 253-272

Lu R (2004) Associations among the components of the East Asian summer monsoon system in the meridional direction. J Meteorol Soc Jpn. Ser. II 82(1):155-165

NCC (National Climate Center) (1998) China's 1998 severe flood and climate extremes. China's Meteorological Press, Beijing, p 137 (in Chinese)

Ninomiya K (2004) Large-and mesoscale features of Meiyu-Baiu front associated with intense rainfalls. In: East Asian Monsoon. pp 404-435

Piao S, Ciais P, Huang Y, Shen Z, Peng S, Li J et al. (2010) The impacts of climate change on water resources and agriculture in China. Nature 467(7311):43-51

Reusch DB, Alley RB, Hewitson BC (2005) Relative performance of self-organizing maps and principal component analysis in pattern extraction from synthetic climatological data. Polar Geogr 29(3): 188-212

Sheridan SC, Lee CC (2011) The self-organizing map in synoptic climatological research. Prog Phys Geogr 35(1):109-119

Smith I (2004) An assessment of recent trends in Australian rainfall. AuMM 53:163-173

Stephan CC, Klingaman NP, Vidale PL, Turner AG, Demory ME, Guo L (2018) A comprehensive analysis of coherent rainfall patterns in China and potential drivers. Part I: interannual variability. Clim Dyn 50(11):4405-4424

Stuecker MF, Timmermann A, Jin FF, McGregor S, Ren HL (2013) A combination mode of the annual cycle and the El Niño/Southern Oscillation. Nat Geosci 6(7):540-544

Stuecker MF, Jin FF, Timmermann A, McGregor S (2015) Combination mode dynamics of the anomalous northwest Pacific anticyclone. J Clim 28(3):1093-1111 
Tian F, Dong B, Robson J, Sutton R (2018) Forced decadal changes in the East Asian summer monsoon: the roles of greenhouse gases and anthropogenic aerosols. Clim Dyn 51(9):3699-3715

Tian F, Dong B, Robson J, Sutton R, Tett SF (2019) Projected near term changes in the East Asian summer monsoon and its uncertainty. Environ Res Lett 14(8):084038

van den Dool HM, Saha S, Johansson Å (2000) Empirical orthogonal teleconnections. Jcli 13:1421-1435

Volonté A, Turner AG, Schiemann R, Vidale PL, Klingaman NP (2021) The interaction of tropical and extratropical air masses controlling East Asian summer monsoon progression. Weather Clim Dyn Discuss 1-29

Wang C (2019) Three-ocean interactions and climate variability: a review and perspective. Clim Dyn 53(7):5119-5136

Wu J, Gao XJ (2013) A gridded daily observation dataset over China region and comparison with the other datasets. Chinese J Geophys 56(4):1102-1111

Wu H, Li X, Schumann GJ-P, Alfieri L, Chen Y, Xu H, Wu Z et al (2021) From China's heavy precipitation in 2020 to a "Glocal" hydrometeorological solution for flood risk prediction. Adv Atmos Sci 38:1-7. https://doi.org/10.1007/s00376-020-0260-y

Xie SP, Zhou ZQ (2017) Seasonal modulations of El Niño-related atmospheric variability: Indo-western Pacific Ocean feedback. J Clim 30(9):3461-3472
Xuan S, Zhang Q, Sun S (2011) Anomalous midsummer rainfall in Yangtze River-Huaihe River valleys and its association with the East Asia westerly jet. Adv Atmos Sci 28(2):387-397

Zhang W, Zhou T (2020) Increasing impacts from extreme precipitation on population over China with global warming. Sci Bull 65(3):243-252

Zhang Q, Zheng Y, Singh VP, Luo M, Xie Z (2017) Summer extreme precipitation in eastern China: mechanisms and impacts. J Geophys Res Atmos 122(5):2766-2778

Zhou B, Wen QH, Xu Y, Song L, Zhang X (2014) Projected changes in temperature and precipitation extremes in China by the CMIP5 multimodel ensembles. J Clim 27(17):6591-6611

Zhou B, Zhai P, Chen Y (2020) Contribution of changes in synopticscale circulation patterns to the past summer precipitation regime shift in Eastern China. Geophys Res Lett 47(12):e2020GL087728

Publisher's Note Springer Nature remains neutral with regard to jurisdictional claims in published maps and institutional affiliations. 